\title{
A CENTRALIZED DISPLAY FOR MISSION MONITORING
}

\author{
Anna C. Trujillo \\ NASA Langley Research Center \\ Hampton, VA 23681
}

\begin{abstract}
Humans traditionally experience a vigilance decrement over extended periods of time on reliable systems. One possible solution to aiding operators in monitoring is to use polar-star displays that will show deviations from normal in a more salient manner. The primary objectives of this experiment were to determine if polar-star displays aid in monitoring and preliminary diagnosis of the aircraft state. This experiment indicated that the polar-star display does indeed aid operators in detecting and diagnosing system events. Subjects were able to notice system events earlier and they subjectively reported the polarstar display helped them in monitoring, noticing an event, and diagnosing an event. Therefore, these results indicate that the polar-star display used for monitoring and preliminary diagnosis improves performance in these areas for system related events.
\end{abstract}

\section{INTRODUCTION}

Humans traditionally experience a vigilance decrement over extended periods of time on reliable systems (Wickens \& Hollands, 2000). As the automation of systems increases, the requirement for this type of monitoring necessitates the display of information to the human operator in such a way that he can notice pertinent deviations in a timely manner. One possible solution to this problem is to use polar-star displays that will show deviations from normal in a more salient manner.

A polar-star display essentially is a polygon (Danchak, 1981). When the polygon is regular, all the parameters represented by the polygon are at or near their expected. A deviation of a vertex indicates a non-normal parameter. For the polar-star displays used in this experiment, each vertex could represent a single parameter (e.g., indicated airspeed) or collection of parameters for a system (e.g., hydraulic system pressure and temperature).

\section{Previous Research}

A polar-star display was chosen primarily because research indicates that using geometric shapes to assist the operator integrate information improves performance (Barnett \& Wickens, 1988; Cooper, 1980; Dinadis \& Vicente, 1999; Jacob, 1978; Jacob \& Egeth, 1976; Jones, Wickens, \& Deutsch, 1990; Wickens \& Hollands, 2000). Trujillo et al., reported research that established the optimal parameters for each vertex (Trujillo \& Schutte, 1999), movement of the display vertices (Bartolone \& Trujillo, 2002; Trujillo, 2002), and where the display should be located (Bartolone \& Trujillo, 2002).

In the context of the flight deck, this display is envisioned to be used primarily for monitoring and preliminary diagnosis. The reasons for this are numerous. First, the information provided on the display qualitatively notifies an operator when a parameter is deviating from normal but it does not quantitatively tell him by how much. Furthermore, in some cases the display does not tell the operator exactly which parameter is deviating. The operator will need to refer to more detailed aircraft instruments to locate this information.

Second, the display provides generalities and not specifics; therefore, it cannot be used for detailed diagnosis (Barnett \& Wickens, 1988). Since the display only provides an overview, it can be used for general failure detection for those parameters included in the polar-star display (Buttigieg \& Sanderson, 1991; Cooper, 1980).

Lastly, other formats, such as the deviation bar graph, are better for more detailed status information (Abbott, 1989, 1990) but the polar-star display may perform better when viewed at a glance (Mahaffey, Horst, \& Munson, 1986). In this case, operators are only monitoring and making preliminary diagnosis with the display, not controlling the system.

Therefore, for this study, two polar-star displays were used that indicated mission parameters and system parameters (Trujillo \& Schutte, 1999). The displays are shown in Figure 1. The polar star on the left shows mission parameters while the polar star on the right shows system parameters. The dotted circle indicates the optimal placement of the vertex given the current aircraft configuration. Even though other research has indicated that directional information is not needed in detecting the movement (Harvey \& Michon, 1974), the movement of the vertices was continuous and directional because of preferences pilots expressed when viewing a polar-star display (Bartolone \& Trujillo, 2002; Trujillo, 2002). Lastly, the polar-star displays were placed in the traditional central area of a glasscockpit set-up; i.e., near the alerting screen (Bartolone \& Trujillo, 2002).

\section{Objectives}

The objectives of this experiment were three-fold. First, determine if the polar-star displays aid in monitoring the
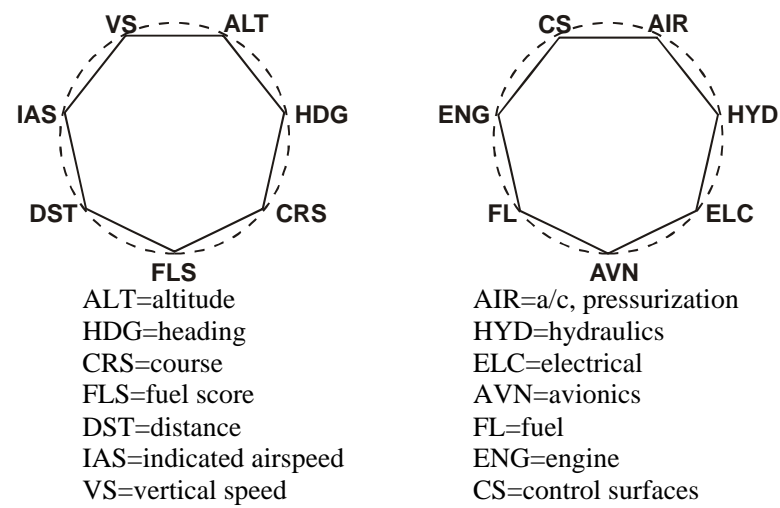

$\mathrm{AIR}=\mathrm{a} / \mathrm{c}$, pressurization HYD=hydraulics ELC=electrical AVN=avionics $\mathrm{FL}=$ fuel ENG=engine $\mathrm{CS}=$ control surfaces

Figure 1. Experiment Polar-Star Displays 
aircraft state. The polar-star displays will concentrate aircraft state information into a central location. This should assist subjects in monitoring the aircraft. With this centralization, it is expected that subjects will generally prefer the new display over the baseline condition. Besides having the aircraft information in a central location, the polar-star display is expected to aid subjects in detecting parameters deviating from normal because of the general design of the display.

Second, see if the display assists with the preliminary diagnosis of aircraft state. Once the subject detects a deviation, the display should inform him of the general nature of the problem. This information will hopefully narrow down the subject's search for information to diagnose the abnormality.

Third, ascertain whether the groupings of aircraft state information were appropriate. Whether the groupings of parameters were logical will become readily apparent from the ease of monitoring and diagnosing of events. This will be reflected in the time it takes subjects to notice an event, and situation awareness (SA) and workload levels when using the new displays.

\section{EXPERIMENT DESIGN}

\section{Experimental variables}

There were two experimental variables: display configuration and event type. Each subject ran half of the data runs with the baseline configuration and half of the data runs with the baseline configuration plus the polar-star displays. Furthermore, half of the non-normal events were events that affected mission parameters and half of the non-normal events affected the system parameters.

Display configuration. Each subject saw the two display configurations: baseline and baseline plus the polar-star displays. The polar-star displays were located to the right of the system displays. The order that the subjects saw the displays was counterbalanced.

Event type. The event types were grouped into either nonnormal events affecting mission parameters (e.g., altitude bust) or non-normal events affecting system parameters (i.e., high cabin altitude). Only one non-normal event would occur during a data run. Each subject had a randomized order of events; although in each display configuration, half of the runs consisted of non-normal events affecting mission parameters and half of the runs consisted of non-normal events affecting system parameters.

\section{Subjects}

Twelve people participated as subjects. All subjects were currently certificated transport pilots who flew glass-cockpit aircraft. The average age of the pilots was 45 years old with an average piloting experience for passenger revenue of 13 years.

\section{Test design}

This experiment was conducted in the Intermediate Design and Evaluation Simulation Lab at the NASA Langley Research Center. The baseline configuration used in this low-to-medium fidelity single-pilot simulator was that of a Citation Ten (a high-end business jet with 2 engines) (Cessna, 1996; FlightSafety International, 1999) with the Honeywell Primus 2000 avionics suite (an advanced glass cockpit) (Honeywell, 1997).

As mentioned earlier, each subject saw the baseline configuration and the polar-star display with non-normal events that encompassed mission parameters or system parameters. With twelve data runs, this means that there were three repetitions for each display configuration and fault type

\section{Dependent measures}

Objective measures. Besides the aircraft state variable information recorded (e.g., altitude and indicated airspeed), additional objective measures were taken. These included the point at which a subject first noticed a non-normal event occurring and when he felt he could diagnose it. This was accomplished by having the subject push buttons labeled "PROBLEM DETECTED" and "PROBLEM DIAGNOSIS" located above the navigation display when he thought he first detected an event and then when he knew what the event was. This time was recorded by the simulation.

Furthermore, his diagnosis of the non-normal event was also recorded after each data run. The subjects' diagnoses were made only to the level of "altitude bust" or "hydraulic quantity."

Subjective measures. After each data run, the subjects answered SA questions about current aircraft state from memory (i.e., amount of fuel left). The SA questions were modeled after Endsley's SAGAT method with the primary difference being that the questions were only asked at the end of each data run (Endsley, 1995a, 1995b, 2000). Subjects also completed a NASA-TLX for workload (Byers, Bittner, \& Hill, 1989; Hart \& Staveland, 1988). After all the simulation runs, each subject completed a final questionnaire that asked for his preferences on the displays just seen.

\section{Procedure}

When a subject first arrived, he was given an overview of this experiment. He then received instructions on how the simulation worked and the new displays. He also was briefed on the route of flight and given a map and flight plan that he was to follow. Lastly, the subject received an overview of the questions he would have to answer after each data run.

After this briefing, the subject went to the simulator where he was able to familiarize himself with the simulation of the aircraft. Before any data runs after a display configuration change, the subjects had two practice runs that behaved the same as the data runs. After the two practice runs, the six data runs with the first display condition were completed.

During the initial part of the data run, subjects were able to familiarize themselves with the aircraft location in space and the aircraft setup. Two to ten minutes into a run an event occurred. When the subject noticed an event, he recorded this with a push of the "PROBLEM DETECTED" button. Once the subject felt he could make a preliminary diagnosis of the event, the simulation stopped and the subject was asked to 
answer SA questions, make a preliminary diagnosis, indicate which screens were the most beneficial to noticing and diagnosing the event, and give a workload rating. When the data runs for the first display configuration were finished, the display configuration was changed and the subject had two practice runs with the new configuration before the six data runs began.

Finally, at the end of all the data runs, subjects completed a questionnaire asking them about their display preferences. Any other comments were also recorded at this time.

\section{Data analysis}

Data were analyzed using SPSS ${ }^{\circledR}$ (SPSS Inc., 2002). The event detection time, event diagnosis time, SA, and NASATLX workload were analyzed using a repeated measures test with diagnosis accuracy as a covariate.

The event detection time and event diagnosis time were computed as the difference between when the subject pushed the "PROBLEM DETECTED" and "PROBLEM

DIAGNOSIS” buttons and the start of the event. The SA measure was a summation of each question the subject answered. The terms in the summation were the absolute value of the subject's answer minus the correct answer divided by the overall standard deviation for that variable. The NASA-TLX workload measures were calculated by doing a simple average of the six measures (i.e., mental, physical, and temporal demand; performance; effort; and frustration level).

The repeated measures for these analyses were the repetitions. In those cases where the repetitions were not significant, a univariate analysis was done. Order effects were checked for but were only present for workload. The end questionnaire data were analyzed using a T-Test. In all cases, significance was set at $\mathrm{p} \leq 0.05$.

Diagnosis accuracy was broken down into 4 categories. The highest category was "Totally Correct," which meant that the subject correctly identified the non-normal event. "Subsystem Correct" indicated that the subject knew the subsystem (e.g., electrical system) but not the exact non-normal event (e.g., battery temperature). The "Mission/System Correct" category meant that the subject understood that the non-normal event affected either the mission or system. Lastly, "Totally Incorrect" meant that the subject did not know whether the non-normal event affected the mission or system.

\section{RESULTS}

\section{Event Detection Time}

For event detection time, diagnosis accuracy $\left(F_{1,128}=8.88\right.$, $\mathrm{p} \leq 0.01)$, event type $\left(F_{1,128}=6.15, \mathrm{p} \leq 0.02\right)$, and event type by display configuration $\left(\mathrm{F}_{1,128}=6.96, \mathrm{p} \leq 0.01\right)$ were all significant. As diagnosis accuracy improved, event detection time increased (Figure 2). Subjects detected mission event types a minute earlier, on average, than they detected system events (99 s and 160 s respectively). Subjects noticed system events faster with the polar-star display than without it, but they detected mission events slower with the polar-star display (Figure 3). Lastly, subjects reported that it was easier to monitor and to notice events using the polar-star display with the greatest improvements for monitoring system status and noticing system events (Table 1).

\section{Event Diagnosis Time}

Diagnosis accuracy $\left(F_{1,128}=13.75, \mathrm{p} \leq 0.01\right)$ and event type $\left(F_{1,128}=3.97, \mathrm{p} \leq 0.05\right)$ were significant for event diagnosis time.

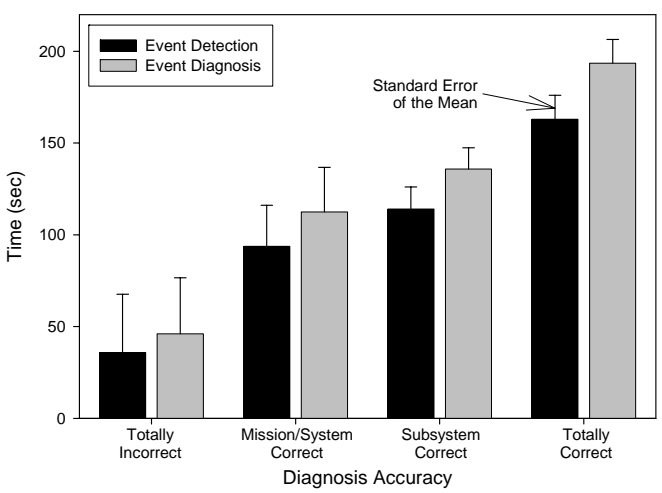

Figure 2. Event Time vs Diagnosis Accuracy

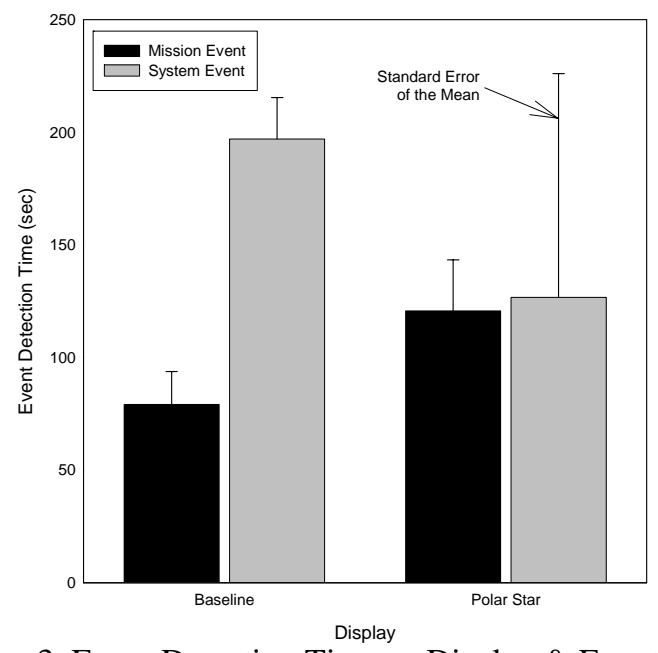

Figure 3. Event Detection Time vs Display \& Event Type

Table 1 - End Questionnaire Subjective Ratings of Polar-Star Display Compared to Baseline Display

\begin{tabular}{|c|c|c|}
\hline Monitoring & $\begin{array}{c}\text { From } \\
\text { Baseline }\end{array}$ & $\begin{array}{c}\text { Standard } \\
\text { Error }\end{array}$ \\
\hline Mission Status & -15.12 & 5.48 \\
\hline System Status & -37.50 & 3.09 \\
\hline Noticing & & \\
\hline Mission Event & -7.50 & 4.92 \\
\hline System Event & -38.10 & 3.04 \\
\hline $\begin{array}{c}\text { Determining } \\
\text { Status of }\end{array}$ & & \\
\hline Mission & -11.55 & 5.32 \\
\hline System & -37.02 & 3.30 \\
\hline $\begin{array}{c}\text { Workload of } \\
\text { Monitoring }\end{array}$ & & \\
\hline Mission Status & -13.21 & 2.76 \\
\hline System Status & -30.71 & 5.56 \\
\hline
\end{tabular}

Note: 100 point scale ( -50 to 50 ) with $0=$ baseline 
As with event detection time, as event diagnosis time increased, diagnosis accuracy also increased (Figure 2). Subjects also diagnosed mission events about a minute before they were able to diagnose system events (124 s and $185 \mathrm{~s}$ respectively).

Finally, subjects reported that it was easier to determine the status of events using the polar-star display again with the greatest improvement for system related parameters (Table 1).

\section{Workload}

Interestingly, the order subjects saw the displays was the only statistically significant factor $\left(F_{1,142}=10.65, \mathrm{p} \leq 0.01\right)$ in the workload analysis. Subjects who saw the baseline condition and then the polar-star display had lower workload ratings by approximately 5\% (28 and 34 respectively out of a 100 point scale where 0 represents lowest workload) than subjects who saw the polar-star display and then the baseline display.

In the end questionnaire, subjects reported that the workload was lower with the polar-star display for monitoring mission status and system status (Table 1). As with event detection time and event diagnosis time, the workload of monitoring system status had a greater improvement than mission status.

\section{Situation Awareness}

For SA, repetitions $\left(F_{3,42}=7.57, \mathrm{p} \leq 0.01\right)$ and repetitions by event type $\left(F_{3,42}=3.16, \mathrm{p} \leq 0.04\right)$ were significant in the repeated measures test. From looking at the data, the first repetition was driving these results. Once it was removed, repetition was barely significant $\left(F_{2,43}=3.24, \mathrm{p} \leq 0.05\right)$ and repetitions by event type was not significant. Therefore, a univariate analysis was done for the repetitions after repetition 1.

For the univariate analysis, event type was statistically significant $\left(F_{1,88}=4.97, \mathrm{p} \leq 0.03\right)$. The system event type SA was higher than for the mission event type SA by approximately $8 \%$ (92 and 85 respectively on a 100 point scale where 100 is the maximum SA); although for both types of events, the SA was very high.

\section{Diagnosis Accuracy}

Event type was significant for diagnosis accuracy $F_{1,128}=14.44$, $\mathrm{p} \leq 0.01$ ). Diagnosis accuracy was higher with system events than for mission events (Figure 4).

\section{DISCUSSION}

In general, subjects were able to detect system events earlier with the polar-star display. Subjects reported that the polar-star display did assist them in monitoring, noticing an event, and status determination. Again, the improvement was for system events rather than for mission events. The polar-star display format for system parameters seems to have increased perceptual sensitivity due to its movement and pattern

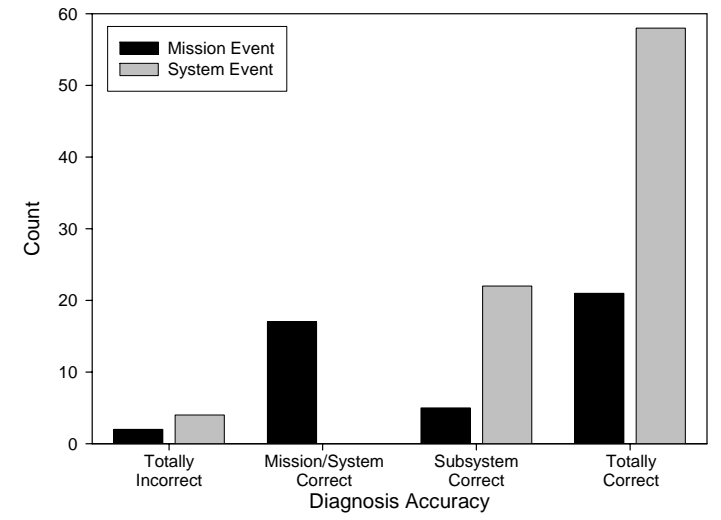

Figure 4. Diagnosis Accuracy vs Event Type

recognition attributes (Donald, 2001; Sanders \& McCormick, 1987). The movement and pattern recognition aspects of the polar-star display may have also aided subjects in making predictions which would obviously affect their detection and diagnosing times (Hawkins, 1993).

Not surprisingly, diagnosis accuracy increased with increasing time. The more time subjects searched for corroborating evidence, the higher their accuracy. Subjects were also more apt to make a diagnosis earlier for mission events although their diagnosis accuracy was only better for system events. This is most likely because system events generally have alerts associated with them that essentially told the subjects the exact nature of the event.

Workload measures improved for the polar-star display by the end questionnaire but the NASA-TLX measurements after each data run did not indicate an improvement using the polarstar display. This overall decrease in workload when using the polar-star display, especially for system parameters, probably reflects the fewer cognitive processes subjects went through when using the display to determine if anything was deviating from normal. A quick glance sufficed rather than comprehending a quantitative parameter value (Sanders \& McCormick, 1987). Workload was also less for subjects who saw the baseline display and then the polar-star display than for subjects who saw the polar-star display before the baseline display. The lower workload for subjects starting with the baseline condition was most likely a result of them starting with a known display setup and then adding the new display. The initial baseline condition gave the subjects time to become comfortable with the new situation without adding the extra stressor of learning to use a new display.

Also, SA improved for system events. For both the workload and SA measures, the differences were statistically significant, but numerically, the differences are small. At the very least, the new display does not increase workload or decrease SA.

One benefit the polar-star display has is to collocate information onto one display. For system parameters, the polar star accomplishes this since system information is otherwise spread out on overhead panels and multifunction displays. Mission information, consisting mainly of aircraft state parameters, is located centrally on the primary flight display and navigation display. Therefore, this information is already aggregated for the operator. 
The polar-star display for system information also does not require the operator to delve into menus to reach the information. Therefore, the system information using the polar-star display becomes readily available like the mission information already on the primary flight and navigation displays.

Lastly, since so much of the system information is layered in multifunction displays and the systems are highly dependable, most operators rely heavily on the alerting system to notify them of deviations. The polar-star display, being in the scan pattern, alerts operators of deviations before an alert range is reached.

Therefore, these results indicate that the polar-star display used for monitoring and preliminary diagnosis improves performance in these areas for system related events.

\section{CONCLUSIONS}

As the automation of systems increase, the requirement for monitoring necessitates the display of information to the human operator in such a way that he can notice pertinent deviations in a timely manner. One possible solution to this problem is to use polar-star displays that will show deviations from normal in a more salient manner.

The greatest benefit the polar-star display appears to derive from the fact that it collocates system information onto a single display. Diagnosis of system events is typically easier than for mission events because the vast majority of system events have alerts associated with them. But monitoring and detecting a system event is more difficult due to this information being spread out and layered. The ability of the polar-star display to aggregate this information seems to be akin to the primary flight display and the navigation display for mission information. Consequently, since mission information is already collocated on the primary and navigation displays and readily available within pilots' scan patterns, the mission polar star did not show the benefits that the system polar-star display did.

Therefore, this current experiment indicated that the polarstar display does aid operators in detecting and diagnosing system events. Subjects were able to notice system events earlier and they subjectively reported the polar-star display helped them in monitoring, noticing an event, and diagnosing an event. Lastly, they reported a slightly lower workload with the polar-star display.

\section{ACKNOWLEDGEMENTS}

The author wishes to thank Anthony Bartolone, now at NASA Langley Research Center, for his help in defining the scenarios and Paul Schutte also of NASA Langley Research Center for his impetus on the initial display concept. The author also wishes to thank John Barry and Thomas Britton of Lockheed-Martin for their expertise in programming the experiment.

\section{REFERENCES}

Abbott, T. S. (1989). Task-Oriented Display Design: Concept and Example (NASA-TM No. 101685). Hampton: NASA Langley Research Center.
Abbott, T. S. (1990). A Simulation Evaluation of the Engine Monitoring and Control System Display (NASA-TP No. 2960). Hampton: NASA Langley Research Center.

Barnett, B. J., \& Wickens, C. D. (1988). Display Proximity in Multicue Information Integration: The Benefits of Boxes. Human Factors, 30(1), 15-24.

Bartolone, A. P., \& Trujillo, A. C. (2002). Glass-Cockpit Pilot Subjective Ratings of Predictive Information, Collocation, and Mission Status Graphics: An Analysis and Summary of the Future Focus of Flight Deck Research Survey (NASA-TM 211419): NASA Langley Research Center.

Buttigieg, M. A., \& Sanderson, P. M. (1991). Emergent Features in Visual Display Design for Two Types of Failure Detection Tasks. Human Factors, 33(6), 631-651.

Byers, J. C., Bittner, A. C., \& Hill, S. G. (1989). Traditional and Raw Task Load Index (TLX) Correlations: Are Paired Comparisons Necessary? Advances in Industrial Ergonomics and Safety, 481-485.

Cessna. (1996). FAA Approved Airplane Flight Manual: Model 750 Citation X (6 ed.). Wichita, KA: Cessna Aircraft Company.

Cooper, L. A. (1980). Recent Themes in Visual Information Processing: A Selected Overview. In Attention and Performance (8 ed., pp. 319-345).

Danchak, M. M. (1981). Techniques for Displaying Multivariate Data on Cathode Ray Tubes with Applications to Nuclear Process Control.

Dinadis, N., \& Vicente, K. J. (1999). Designing Functional Visualizations for Aircraft Systems Status Displays. IJAP, 9(3), 29.

Donald, C. (2001). Vigilance. In J. Noyes \& M. Bransby (Eds.), People in Control: Human Factors in Control Room Design (pp. 315). UK: The Institute of Electrical Engineers.

Endsley, M. R. (1995a). Measurement of Situation Awareness in Dynamic Systems. Human Factors, 37(1), 65-84.

Endsley, M. R. (1995b). Toward a Theory of Situation Awareness in Dynamic Systems. Human Factors, 37(1), 32-64.

Endsley, M. R. (2000). Direct Measurement of Situation Awareness: Validity and Use of SAGAT. In M. R. Endsley \& D. J. Garland (Eds.), Situation Awareness Analysis and Measurement (pp. 21). Mahwah, NJ: Lawrence Erlbaum Assoc.

FlightSafety International. (1999). Citation X Pilot Training Manual. Flushing, NY: FlightSafety International, Inc.

Hart, S. G., \& Staveland, L. E. (1988). Development of a NASA-TLX (Task Load Index): Results of Empirical and Theoretical Research. In P. S. Hancock \& N. Meshkati (Eds.), Human Mental Workload (pp. 139-183). Amsterdam: Elsevier Science Publishers B. V.

Harvey, L. O., Jr., \& Michon, J. A. (1974). Detectability of Relative Motion as a Function of Exposure Duration, Angular Separation, and Background. Journal of Experimental Psychology, 103(2), 317-325.

Hawkins, F. H. (1993). Human Factors in Flight (2 ed.). Brookfield, VT: Ashgate Publishing Co.

Honeywell. (1997). Primus 2000 Integrated Avionics Flight Control System for the Citation X: Pilot's Manual. Phoenix, AZ: Business and Commuter Avionics Systems, Honeywell.

Jacob, R. J. K. (1978). Facial Representation of Multivariate Data. In P. C. C. Wang (Ed.), Graphical Representation of Multivariate Data (pp. 143168). Washington, D.C.: Naval Research Laboratory.

Jacob, R. J. K., \& Egeth, H. E. (1976). The Face as a Data Display. Human Factors, 18(2), 189-200.

Jones, P. M., Wickens, C. D., \& Deutsch, S. J. (1990). The Display of Multivariate Information: An Experimental Study of an Information Integration Task. Human Performance, 3(1), 1-17.

Mahaffey, D. L., Horst, R. L., \& Munson, R. C. (1986). Behavioral Comparison of the Efficacy of Bar Graphs and Polar Graphics for Displays of System Status. Paper presented at the IEEE.

Sanders, M. S., \& McCormick, E. J. (1987). Human Factors in Engineering and Design (6 ed.): McGraw-Hill Publishing Co.

SPSS Inc. (2002). SPSS for Windows (Version 11.5): SPSS Inc.

Trujillo, A. C. (2002). Vertex Movement for Mission Status Graphics: A PolarStar Display (No. NASA-TM 211414): NASA Langley Research Center.

Trujillo, A. C., \& Schutte, P. C. (1999). Non-Traditional Displays for Mission Monitoring. Paper presented at the American Nuclear Society 1999 Winter Meeting and Embedded Topical Meetings.

Wickens, C. D., \& Hollands, J. G. (2000). Engineering Psychology and Human Performance (Third ed.). 